УДК 338.48

DOI 10.18101/2304-4446-2020-1-10-19

\title{
ОСОБЕННОСТИ РЕАЛИЗАЦИИ КЛИЕНТООРИЕНТИРОВАННОЙ ПОЛИТИКИ В ОГАНИЗАЦИИ САНАТОРНО-КУРОРТНОЙ СФЕРЫ
}

\section{(C) Донскова Людмила Ивановна}

кандидат экономических наук, доцент, Алтайский государственный университет Россия, 665049, г. Барнаул, пр. Ленина, 61 E-mail: donskova@yandex.ru

\section{(C) Редькин Александр Германович}

кандидат географических наук, доцент, Алтайский государственный университет Россия, 665049, г. Барнаул, пр. Ленина, 61 E-mail: redkin@asu.ru

\section{(C) Макаров Андрей Анатольевич}

кандидат экономических наук, доцент, Московский гуманитарный университет Россия, 111395, г. Москва, ул. Юности, 5 E-mail:mir210mir@yandex.ru

\section{(C) Чикалова Людмила Степановна}

кандидат экономических наук, доцент,

Смоленский областной казачий институт промышленных технологий и бизнеса (филиал Московского государственного университета технологий и управления им. К. Г. Разумовского (ПКУ))

Россия, 215110, г. Вязьма, ул. Ленина, 77

E-mail:mir210mir@yandex.ru

Вопросы, связанные с клиентоориентированной политикой в сервисной экономике, имеют особо важное значение, так как ее разработка, внедрение и реализация определяют условия, которые обеспечивают удовлетворенность потребителей уровнем сервиса, качеством обслуживания, а также экономического и социального роста сервисной организации в целом. На примере организации санаторно-курортной сферы проанализированы аспекты реализации клиенториентированной политики, в которой системообразующим фактором является процесс взаимодействия потребителя и производителя, что в конечном итоге позволяет обеспечить доминирующее развитие обслуживающей деятельности. При этом исследование клиентоориентированности и ее произведенная оценка в количественных и качественных показателях характеризуют актуальные аспекты деятельности санаторно-курортной организации, включая ее следующие основные характеристики: качество обслуживания, лояльность потребителей, стратегические приоритеты конкурентоспособности.

Ключевые слова: сфера услуг; санаторно-курортная сфера; лечебнопрофилактические организации; клиентоориентированная политика; взаимодействие потребителя и производителя; удовлетворенность клиентов; стандарты обслуживания. 
Л. И. Донскова, А. Г. Редькин, А. А. Макаров, Л. С. Чикалова. Особенности реализации клиентоориентированной политики в организации санаторно-курортной сферы

\section{Для цитирования}

Донскова Л. И., Редькин А. Г., Макаров А. А., Чикалова Л. С. Особенности реализации клиентоориентированной политики в организации санаторно-курортной сферы // Вестник Бурятского государственного университета. Экономика и менеджмент. 2020. № 1. С. 10-19.

В последние годы качественно новое развитие получила сфера услуг, являющаяся наиболее прибыльной отраслью и способствующая увеличению удельного веса в структуре ВВП, числа рабочих мест и диверсификации экономики регионов. Как отмечает источник, «в мире доля услуг в структуре ВВП за последние годы составила в США 75,5\%, Великобритании - 72,6\%, во Франции - 72,8\%, значительно превышая показатели производственной сферы. Также происходит и увеличение числа занятых, доля которых составляет в США - 77,6\%, Великобритании - 76,3\%, во Франции - 71,4\%» [7]. Тенденции возрастания роли сферы услуг начались в середине 1970-х гг. в связи с переходом ряда западных стран к новому «технологическому укладу», обусловленному усилением значения научно-технических факторов $[12 ; 13]$.

Под влиянием экономических и общественных изменений в развитых странах происходит увеличение объемов и усложнение структуры потребления услуг, в которой возрастают информационные и социально-культурные (в т. ч. образования и туризма). По нашему мнению, удовлетворение с их помощью духовных, социокультурных потребностей человека будет содействовать росту его образования и самореализации, накоплению «человеческого капитала»; при этом расширение количества разнообразных коммуникаций предопределяет успех в профессиональной деятельности.

В нашей стране успешно функционирует сеть сервисных организаций, предоставляющих образовательные, информационные, консалтинговые, медицинские, финансовые, деловые и другие услуги. Их важным конкурентным преимуществом является клиентоориентированный подход, предполагающий удовлетворение потребностей, повышение уровня и качества обслуживания клиентов. Предприятия сферы услуг существенно зависят от особенностей конкурентного функционирования, обусловленных необходимостью привлечения новых клиентов и удержания текущих; следовательно, должны понимать их текущие и будущие потребности, отвечать требованиям, стремиться превзойти ожидания, что предполагает, как отмечает исследователь, «высочайшее значение ориентации предприятия на максимальное удовлетворение клиента» [3].

Одновременно ужесточаются требования к предприятиям, оказывающим различные услуги. В настоящее время на многих предприятиях разработаны стандарты и регламенты обслуживания, но, по нашему мнению, этого недостаточно, так как для обеспечения конкурентоспособности необходима ориентация на клиента. Ее важность обусловлена тем, что весомую часть прибыли хозяйствующие субъекты получают за счет повторного обращения клиента, выстраивая долгосрочные (клиентоориентированные) отношения с ними. В связи с этим становятся актуальными вопросы мониторинга изменения потребностей клиентов, повышения потребительской значимости продукции и услуг, обучения персонала, его ориентированности на клиента $[14 ; 15 ; 18]$. 
Обзор публикаций по вопросам клиентоориентированности, качества сервиса, удовлетворенности клиентов показывает, что они затрагивают как общие (сущность и влияние клиентоориентированности на конкурентные преимущества организации сферы услуг и торговли, проблемы ее оценки), так и специфические (оценка качества санаторно-курортных, гостиничных и туристических услуг, подготовка специалистов для сферы туризма и гостеприимства) понятия [1-2; 4 $11 ; 16-17 ; 19-25 ; 27-28]$.

Под клиентоориентированностью понимают стратегию компании, направленную «на учет и удовлетворение потребностей клиента и формирование максимально комфортных отношений с ним» [23]. Имеется мнение о том, что «клиентоориентированность - оценка, которую получает компания от своего клиента в результате взаимодействия с ним» [26].

Нам импонирует следующее определение клиентоориентированности: «Концепция бизнеса, включающая комплекс мероприятий, направленных на удовлетворение и формирование потребностей клиентов (конечных потребителей и торговых посредников), реализуемая на всех уровнях менеджмента во всех функциональных подразделениях, ориентированная на инновационное (проактивное) развитие с целью достижения устойчивого конкурентного преимущества» $[10 ; 30]$.

В связи с этим клиентоориентированный подход характеризует различные аспекты, а именно:

- ценности организации, которые формируют понимание значения клиента для ее успеха;

- ядро или элемент стратегии компании (ориентированность бизнеспроцессов на клиентов);

- $\quad$ функция маркетинга (что предполагает определение потребностей представителей целевой аудитории);

- система и характер отношений с потребителями услуг $[10 ; 24 ; 28 ; 29]$.

Известно, что отраслевые хозяйствующие субъекты являются сложными объектами социально-экономической системы, которые взаимодействуют со своим окружением, характеризуются различными связями и процессами, включая межличностные коммуникации [4; 12; 19]. В системе «сервис» важным «системообразующим» фактором в момент предоставления и потребления услуг является процесс взаимодействия потребителя и их производителя.

Как отмечает источник, «экономическое взаимодействие связано с использованием ценностей (ресурсов) и направлено на извлечение выгоды, однако оно носит и социальный характер. Объективной стороной здесь выступают связи, не зависящие от отдельных людей, но контролирующие содержание и характер их взаимодействия (отношения внутри группы как «социальная роль - социальная роль»). Под субъективной стороной социального взаимодействия понимается сознательное отношение индивидов как «личность - личность», основанных на ожиданиях и соответствующем поведении (социально-психологические отношения, складывающиеся в конкретных общностях в определенное время)» [7].

Клиентоориентированность можно разделить по типу клиентов и поведению сотрудников. К примеру, по типу клиента выделяют внешнюю (сотрудники данной организации) и внутреннюю (лица, обратившиеся в организацию для полу- 
Л. И. Донскова, А. Г. Редькин, А. А. Макаров, Л. С. Чикалова. Особенности реализации клиентоориентированной политики в организации санаторно-курортной сферы

чения услуг). По типу поведения сотрудника - функциональная и отношенческая. Так, первая рассматривает сотрудника компании как человека, знающего все аспекты работы, способного правильно представить продукт. В сфере сервиса важно умение сотрудников устанавливать доверительные отношения, что подразумевает выполнение не только своей функциональной роли, но и роли напарника, способного понять клиента и решить его проблему.

Таким образом, клиентоориентированность - подход современного бизнеса, согласно которому приоритет принадлежит принципу удовлетворения потребностей клиентов, соответствия их ожиданиям при осуществлении всех направлений организационной деятельности [29]. При этом процесс взаимодействия между потребителем и производителем характеризуется полезным эффектом, обусловленным в т.ч. и наличием индивидуальности, опыта и мастерства со стороны персонала организации.

Взаимосвязь клиентоориентированности не только с бизнес-процессами, но и с качеством и уровнем сервиса, удовлетворенностью клиентов выступает интегрированным показателем, характеризующим текущую и стратегическую деятельность сервисного предприятия. Например, для организации санаторнокурортной сферы выделены такие элементы клиентоориентированности:

- функциональные (профессионализм персонала, внимательность к гостям, доступность информации, время ожидания услуг);

- материальные (чистота и порядок в организации, готовность номера к приему гостей, питание, оснащенность медицинским оборудованием);

- $\quad$ комплексные (отражают организацию работ структурных подразделений по обслуживанию отдыхающих).

Для определения этого показателя целесообразно осуществлять анализ показателей финансово-хозяйственной деятельности, важным из которых, по нашему мнению, будет прирост выручки («материализация» отношений, ориентированных на клиента). В этом случае можно предвидеть поведение клиента: его возвращение в компанию, рекомендации своему окружению, пожелания по улучшению обслуживающей деятельности, что в совокупности помогает повысить качество сервиса, совершенствовать бизнес-процессы и получить дополнительный доход [12; 19;24; 30].

Проводится исследование поведения клиентов и сотрудников в организации по вопросам качества обслуживания, уровня удовлетворенности клиентов. При этом важны стандарты в организации и контроль за их соблюдением в соответствии с принятыми критериями. Анализ уровня удовлетворенности клиента качеством обслуживания, оценка их лояльности и повышение ее уровня, распространение положительной практики обслуживания - это одни из целей клиентоориентированного бизнеса.

ООО «Санаторий “Эдем”», выбранный нами в качестве объекта исследования, является многопрофильным лечебно-профилактическим учреждением (г. Белокуриха Алтайский край), оказывающим комплексное санаторно-курортное лечение на основе природных факторов с применением новейших методик и современного оборудования. Политика обслуживания в санатории - комплекс мероприятий, направленных на удовлетворение потребностей гостей и получение на этой основе постоянного дохода. 
Анализ финансово-экономических показателей организации показывает, что за период 2016-2018 гг. отмечается рост выручки и прибыли от продаж. Динамика показателей рентабельности свидетельствует о существенном росте выручки относительно расходной части, что свидетельствует, по нашему мнению, о повышении эффективности деятельности организации за счет активизации маркетинговой работы и политики клиентоориентированности.

В управлении организацией осуществляется регулярная обратная связь с клиентами, реализуемая в форме мониторинга отзывов гостей об удовлетворенности качеством услуг. Опрос гостей ведется на сайте для оценки удовлетворенности услугами проживания, питания и лечения. Также отдыхающему в санатории предлагается заполнить анкету с целью выявления сильных и слабых сторон обслуживания.

Однако следует отметить, что анализ мониторинга не всегда носит системный характер: не ведется статистика неудовлетворенных клиентов, повторных продаж и отчетность по «жизненному циклу клиента». Опрос, в частности, не детализирован, не раскрывает причин недовольства гостем особенностями обслуживания. При этом работа с жалобами носит спонтанный характер, проводится без проведения предупреждающих мер.

Основными документами, регламентирующими политику обслуживания в ООО «Санаторий “Эдем”», являются «Стандарт этики поведения гостиничного персонала» и «Стандарт внешнего вида гостиничного персонала». Эти документы устанавливают принципы поведения и внешнего вида обслуживающего персонала, которые должны реализоваться в его повседневной деятельности и взаимоотношениях с гостями санатория.

Результаты мониторинга соблюдения стандартов по 10-балльной шкале (10 - max... 1 - min) показывают, что перечисленные требования, направленные на поддержание высокого уровня клиентоориентированности, в целом выполняются обслуживающим персоналом. Периодические проверки качества обслуживания гостей дают высокие показатели (табл. 1).

Преимуществом политики обслуживания гостей в ООО «Санаторий “Эдем”» являются ее комплексный подход и отсутствие формализованного отношения руководства и персонала организации к предъявляемым требованиям обслуживания. К главному недостатку можно отнести то, что существующие стандарты в основном направлены на работников гостиничного комплекса санатория, без учета обслуживания гостей в ресторане и лечебном комплексе.

Таблица 1

Обобщенные результаты контроля соблюдения стандартов в санаторно-курортной организации

\begin{tabular}{|l|c|c|c|c|}
\hline $\begin{array}{c}\text { Критерий оцен- } \\
\text { ки }\end{array}$ & $\begin{array}{c}\text { Номерной фонд } \\
(1-10)\end{array}$ & $\begin{array}{c}\text { Служба приема и } \\
\text { размещения } \\
(1-10)\end{array}$ & $\begin{array}{c}\text { Лечебный ком- } \\
\text { плекс } \\
(1-10)\end{array}$ & $\begin{array}{c}\text { Ресторан } \\
(1-10)\end{array}$ \\
\hline $\begin{array}{l}\text { Стандарты } \\
\text { поведения }\end{array}$ & 7 & 9 & 8 & 8 \\
\hline $\begin{array}{l}\text { Стандарты } \\
\text { внешнего вида }\end{array}$ & 7 & 10 & 9 & 9 \\
\hline
\end{tabular}


Л. И. Донскова, А. Г. Редькин, А. А. Макаров, Л. С. Чикалова. Особенности реализации клиентоориентированной политики в организации санаторно-курортной сферы

Для более глубокого исследования клиентоориентированности проведено анкетирование отдыхающих (310 чел.) во время их пребывания в санатории на предмет удовлетворенности услугами и обслуживанием. В качестве оценочной шкалы использовалась 10-балльная (10 баллов - максимальное удовлетворение; 1 балл - минимальное удовлетворение).

Вопросы разработанной анкеты можно условно разделить на несколько блоков, направленных на оценку удовлетворенности:

1) функциональным качеством услуг (поведение персонала, внешний вид, отношение к гостю, профессионализм);

2) материальным обеспечением процесса предоставления услуг (месторасположение, оснащение и оборудование санатория, дизайн и чистота);

3) качеством услуг в комплексе (организация работы в целом по службам);

4) лояльности и пожеланий потребителей по отношению к услугам санатория.

Больше всего оценок получили показатели материального обеспечения $(8,33)$. Это, на наш взгляд, быстрее всего достигается обновлением материальнотехнической базы. Среднюю оценку получил уровень удовлетворенности функциональным качеством $(8,16)$, элементы которого зависят от деятельности и квалификации персонала. При исследовании функционального качества услуг наибольшее количество баллов получили критерии: «Время ожидания получения услуг» $(82 \%)$ и «Информационная обеспеченность» (89\%). При анализе материального обеспечения процесса предоставления услуг значимое количество баллов получили критерии: «Место расположения санатория» (80\%), «Интерьер и дизайн помещений» $(72 \%)$.

В целом наибольшее количество гостей санатория (60\%) дали высокую оценку критерию «Организация приема и размещения гостей», а наименьший усредненный балл получил критерий «организация досуга, анимация».

Таким образом, уровень удовлетворенности гостей санатория достаточно высокий (8,33 по средневзвешенной арифметической), при этом 80,4\% всех опрошенных пожелали посетить его вновь. Эти данные свидетельствуют о реализации организацией клиентоориентированного подхода.

С целью формирования предложений по совершенствованию клиентоориентированной политики методом экспертных оценок был проведен опрос фокусгруппы из представителей топ-менеджмента и руководителей служб «контактной зоны», посвященный ее влиянию на стратегию организации. В результате $68 \%$ экспертов считают клиентоориентированность важным элементом стратегии, а остальные эксперты признали, что в их организациях «работа над внедрением данной философии идет полным ходом».

Известно, что для формирования клиентоориентированности обслуживания необходимо создавать и совершенствовать элементы корпоративной культуры. Также в контексте реализации стратегии для его формирования у персонала рекомендуется следующий алгоритм: подбор сотрудников, обладающих определенными качествами, постоянное их обучение клиентоориентированности (на основе принятых в организации стандартов обслуживания клиентов), систематический и постоянный анализ уровня и качества обслуживания клиентов. При создании стандартов обслуживания целесообразно соблюдать следующие правила: они должны учитывать специфику отрасли; опираться на ожидания клиента; 
быть понятными, применимыми в реальных ситуациях, соблюдаться всеми сотрудниками. Данные стандарты позволяют сокращать временные затраты на адаптацию новых сотрудников, а при подборе кандидатов развивают у них такую компетенцию, как «Клиентоориентированность обслуживающей деятельности».

В таблице 2 представлены некоторые подходы к выработке данной компетенции, ориентированной как на клиента, так и на сотрудника.

Таблица 2

Подходы к развитию компетенции «Клиентоориентированность обслуживающей деятельности»

\begin{tabular}{|c|c|}
\hline \multicolumn{2}{|c|}{ Сравнение подходов к развитию клиентоориентированности } \\
\hline Внешняя (в центре - клиент) & Внутренняя (в центре - сотрудник) \\
\hline $\begin{array}{l}\text { Акцент на то, что должен делать сотрудник } \\
\text { (соответствие стандартам) }\end{array}$ & $\begin{array}{l}\text { Акцент на должность и важность того, что дела- } \\
\text { ет работник }\end{array}$ \\
\hline \multicolumn{2}{|c|}{ Развитие навыков компетенции «Эффективное слушание» } \\
\hline $\begin{array}{l}\text { Обобщение и трансляция навыков «эффектив- } \\
\text { ного слушания» } \\
\text { Тренировка в диалогах }\end{array}$ & $\begin{array}{l}\text { Выявление трудностей эффективного общения с } \\
\text { описанием существующих помех и сложностей } \\
\text { этого процесса для сотрудника и слушателя, что } \\
\text { позволяет оценить важность решаемой задачи }\end{array}$ \\
\hline \multicolumn{2}{|c|}{ Умение задавать вопросы } \\
\hline $\begin{array}{l}\text { Определение видов вопросов, предназначен- } \\
\text { ных для клиентов; формирование их перечня }\end{array}$ & $\begin{array}{l}\text { Рассмотреть, какое значение имеют вопросы } \\
\text { для сотрудника (позволяют получить дополни- } \\
\text { тельную информацию, подстраховаться на слу- } \\
\text { чай недовольства клиента). Предложить самому } \\
\text { составить аргументированные вопросы }\end{array}$ \\
\hline \multicolumn{2}{|c|}{ Работа с претензиями } \\
\hline $\begin{array}{l}\text { Типизация «сложных клиентов». Разработка и } \\
\text { реализация алгоритма взаимодействия с каж- } \\
\text { дым из них }\end{array}$ & $\begin{array}{l}\text { Довести до сведения сотрудников, что «слож- } \\
\text { ный клиент», как правило, хочет дальше рабо- } \\
\text { тать с компанией, но некоторые моменты в } \\
\text { обслуживании его не устраивают. } \\
\text { Найти причины, мешающие работать с таким } \\
\text { клиентом. } \\
\text { Предложить каждому сотруднику составить } \\
\text { свою типологию клиентов. } \\
\text { Сделать упор на индивидуальные эффективные } \\
\text { стратегии коммуникаций }\end{array}$ \\
\hline
\end{tabular}

В связи с этим программу обучения клиенториентированности целесообразно реализовывать с упором на деятельность сотрудника сервисной организации, показав, что клиентоориентированное поведение выгодно ему самому.

Специалисты в сервисе должны обладать необходимым набором компетенций: высокий уровень креативности (сервис предполагает поиск и «конструирование» новых услуг) и коммуникативных способностей (необходимость за минимальный срок устанавливать контакт с потенциальным потребителем); особый тип мышления (предполагающий выполнение большого количества задач); на основе природной наблюдательности и навыков способность к экспрессдиагностике; умение вести себя профессионально в конфликте; в любое время суток обеспечивать высокое качество обслуживания. 
Л. И. Донскова, А. Г. Редькин, А. А. Макаров, Л. С. Чикалова. Особенности реализации клиентоориентированной политики в организации санаторно-курортной сферы

Особенно подчеркнем роль и значение новой информации, получаемой проведением постоянных исследований, предполагающих составление отчетности с отражением количества, соотношения и динамики удовлетворенных/неудовлетворенных клиентов, учета пожеланий гостей.

Обобщая представленную информацию, отметим, что реализация эффективной клиентоориентированной политики в организации санаторно-курортной сферы позволяет улучшить репутацию через лидерство на целевом рынке и создание/поддержание ее положительного имиджа; уменьшить риск с помощью привлечения более широкого круга клиентов и сглаживания сезонных колебаний, что в целом будет способствовать повышению ее конкурентоспособности на рынке.

\section{Литература}

1. Балабанова А. В., Журавлев Г. Т. Мотивы покупки товара (услуги) // Ученые записки Российской академии предпринимательства. 2015. № 43. С. 237-251.

2. Башина О. Э., Завражин А. В., Карманов М. В. Оздоровительный туризм: особенности управления и прикладного анализа: монография. М.: Изд-во МЭСИ, 2014. $194 \mathrm{c}$.

3. Бусаркина В. В. Понятие клиентоориентированности предприятия и проблемы ее оценки // Проблемы современной экономики. 2007. № 4 (24). С. 179-183.

4. Гапоненко А. Л., Савельева М. В. Традиционные и новые факторы конкурентоспособности организаций // Проблемы теории и практики управления. 2015. № 5. С. 117124.

5. Денисова И. Н. Особенности маркетинга взаимоотношений в деятельности потребительской кооперации // Экономика. Статистика и информатика. Вестник УМО. 2011. № 1. С. 54- 58 .

6. Депутатова Е. Ю., Перельман М. А. Пути формирования потребительской лояльности в розничной торговле // Экономика и предпринимательство. 2019. № 3(104). C. $737-741$.

7. Донскова Л. И. Современный подход к изучению сервиса как социальной системы // Идея и идеалы. 2011. Т. 2, № 4. С. 52-59.

8. Донскова Л. И., Зорина Л. Г. Факторы, влияющие на удовлетворенность и лояльность потребителей санаторно-курортных услуг: российский опыт // Наука и туризм: стратегии взаимодействия: сборник статей / под ред. А. Г. Редькина. Барнаул: Изд-во Алт. ун-та, 2018. Вып. 8. С. 4-12.

9. Донскова Л. И., Макаров А. А. Санаторно-курортное обеспечение военнослужащих и членов их семей в контексте реализации социального туризма //Актуальные проблемы гуманитарных и социально-экономических наук. 2019. № 13 (67). С. 59-65.

10. Ефремова М. В., Чкалова О. В. Обобщение и систематизация подходов к определению «клиентоориентированность» // Вестник Нижегородского национального университета им. Н. И. Лобачевского. Сер. Социальные науки. 2016. № 2(42). С.17-24.

11. Зинцова М. В. Организация розничной продажи товаров: маркетинговый подход: учеб. пособие. М.: Дашков и К, 2011. 89 с.

12. Императивы бизнеса / под ред. Ю. Н. Клещевского, И. А. Кудряшовой; Кемеровский институт (филиал) РЭУ им. Г. В. Плеханова. Кемерово: Изд-во Кемеров. ин-та (филиала) РЭУ им. Г. В. Плеханова, 2017. 280 с.

13. Калашникова Ю. В. Шестой технологический уклад и современная научная политика РФ // Научный альманах. 2015. № 8 (10). С. 201-208.

14. Калугина С. А., Лебедева Т. П. Современные подходы к определению качества обслуживания покупателей // Вестник Академии. 2016. № 4. С. 95-100. 
15. Калугина С. А., Лебедева Т. П., Макаров А. А. Оценка качества работы персонала как фактор формирования клиентоориентированности компании // Вестник Академии. 2017. № 1. C. 59-64.

16. Комаров В. М. Управление лояльностью потребителей в банковском секторе российской экономики // Экономика. Бизнес. Банки. 2016. № 58. С. 199-207.

17. Комаров В. М., Омарова Б. А. Управление цифровыми решениями сервисных предприятий // Путеводитель предпринимателя. 2018. № 38. С.83-90.

18. Латышова Л. С., Ойнер О. К., Сяглова Ю. В. Клиентоориентированность как основа устойчивого бизнеса - сущность и признаки клиентоориентированности компании // Механизация строительства. 2015. № 10 (856). С. 59-62.

19. Максанова Л. Б.-Ж., Данилова 3. А. Программно-проектный подход в системе управления развитием регионального туризма // Вестник Бурятского государственного университета. Экономика и менеджмент. 2019. № 3. С. 49-55.

20. Отто О. В., Редькин А. Г. Анализ сезонности в лечебно-оздоровительном туризме: региональный аспект // Вестник Кемеровского государственного университета. 2015. № 2-7 (62). С.239-243.

21. Саргаева Н. Ю. Оценка качества санаторно-курортных услуг и приоритетные направления их повышения // Вестник КарГУ. 2018. С. 22-25.

22. Симакина М. А. Современные маркетинговые технологии в розничной торговле // Бюллетень науки и практики. 2019. Т. 5, № 3. С. 299-304.

23. Смирнов Ю. И. Клиентоориентированность как способ получения дополнительной прибыли. М.: Флинта, 2013.

24. Торговое дело: коммерция, маркетинг, менеджмент. Теория и практика: Монография / под науч. ред. Д. И. Валигурского. М.: Дашков и К, 2017. 410 с.

25. Туманов И. Ю. Оценка качества санаторного обслуживания организации // Экономика и бизнес: теория и практика. 2016. № 9. С. 91-96.

26. Харский К. Клиентоориентированность: четыре шага и еще один прыжок // Психология и бизнес. 2016 [Электронный ресурс]. URL: https://psycho.ru/library/3558 (дата обращения: 20.10.2019).

27. Цыренов Д. Д., Стробел Д. Клиентоориентированный подход к управлению предприятием // Вестник Бурятского государственного университета. Экономика и менеджмент. 2014. № 2. С. 69-81.

28. Шальнова О. А., Зинцова М. В., Ребрикова Н. В. Технологии формирования потребительской лояльности в розничной торговле: монография. М.: Дашков и $\mathrm{K}^{\circ}, 2014$. $107 \mathrm{c}$.

29. Шуравина Е. Н. Клиентоориентированность как важный фактор совершенствования системы управления современным бизнесом // Вестник Самарского государственного экономического университета. 2013. №6 (104). С. 146-149.

30. Яшина О. В. Модель и механизмы стратегического управления клиентоориентированной корпорацией: автореф. дис. ... канд. экон. наук: 08.00.05. Пенза, 2013. 25 с. 


\section{IMPLEMENTATION OF CUSTOMER-CENTRIC POLICY \\ IN ORGANIZATION OF HEALTH RESORT SERVICES}

Lyudmila I. Donskova

Cand. Sci. (Econ.), A/Prof.,

Altai State University

61 Lenina Prospect, Barnaul 665049, Russia

E-mail: mir210mir@yandex.ru

Aleksandr G. Redkin

Cand. Sci. (Geogr.), A/Prof.,

Altai State University

61 Lenina Prospect, Barnaul 665049, Russia

E-mail: mir210mir@yandex.ru

Andrey A. Makarov

Cand. Sci. (Econ.), A/Prof.,

Moscow University for the Humanities,

5 Yunosti St., Moscow 111395, Russia

E-mail:mir210mir@yandex.ru

\section{Lyudmila S. Chikalova}

Cand. Sci. (Econ.), A/Prof.,

Smolensk Regional Cossack Institute of Industrial Technologies and Business

(branch of Razumovsky Moscow State University of Technology and Management

(First Cossack University))

77 Lenina St., Vyazma 215110, Russia

E-mail: mir210mir@yandex.ru

The issues related to customer-centric policy of service economy are of special importance since its implementation determines the conditions that ensure customer satisfaction with the level of service, quality of service, as well as the economic and social growth of service organization as a whole. We have analyzed the aspects of implementing customer-centric policy on the example of health resort services, where the process of interaction between consumers and service providers is a systemically important factor influencing the development of service activities. At the same time, the customer research and assessment of the quantitative and qualitative indicators of client-centeredness characterize the current trends in the activities of prevention and treatment facilities, including its main characteristics, such as quality of service, customer loyalty, strategic priorities of competitiveness.

Keywords: service industry; health resort services; prevention and treatment facilities; customer-centric policy; interaction of manufacturers and consumers; customer satisfaction; service standards. 